Subscriber access provided by Caltech Library

\title{
Article
}

\section{Correlating Oxidation State and Surface Area to Activity from Operando Studies of Copper CO Electroreduction Catalysts in a Gas-fed Device}

Soo Hong Lee, Ian Sullivan, David M. Larson, Guiji Liu, Francesca Maria Toma, Chengxiang Xiang, and Walter S. Drisdell

ACS Catal., Just Accepted Manuscript • DOI: 10.1021/acscatal.0c01670 • Publication Date (Web): 25 Jun 2020

Downloaded from pubs.acs.org on June 25, 2020

\section{Just Accepted}

"Just Accepted" manuscripts have been peer-reviewed and accepted for publication. They are posted online prior to technical editing, formatting for publication and author proofing. The American Chemical Society provides "Just Accepted" as a service to the research community to expedite the dissemination of scientific material as soon as possible after acceptance. "Just Accepted" manuscripts appear in full in PDF format accompanied by an HTML abstract. "Just Accepted" manuscripts have been fully peer reviewed, but should not be considered the official version of record. They are citable by the Digital Object Identifier (DOI®). "Just Accepted" is an optional service offered to authors. Therefore, the "Just Accepted" Web site may not include all articles that will be published in the journal. After a manuscript is technically edited and formatted, it will be removed from the "Just Accepted" Web site and published as an ASAP article. Note that technical editing may introduce minor changes to the manuscript text and/or graphics which could affect content, and all legal disclaimers and ethical guidelines that apply to the journal pertain. ACS cannot be held responsible for errors or consequences arising from the use of information contained in these "Just Accepted" manuscripts. 


\title{
Correlating Oxidation State and Surface Area to Activity from Operando Studies of Copper CO Electroreduction Catalysts in a Gas-fed Device
}

\author{
Soo Hong Lee, ${ }^{\dagger, \#}$ Ian Sullivan,,$* \#$ David M. Larson, ${ }^{\dagger}$ Guiji Liu, ${ }^{\dagger}$ \\ Francesca M. Toma, ${ }^{\dagger}$ Chengxiang Xiang, ${ }^{*}, \star$ and Walter S. Drisdell ${ }^{*}, \dagger$ \\ $\dagger$ Joint Center for Artificial Photosynthesis and Chemical Sciences Division, Lawrence Berkeley \\ National Laboratory, 1 Cyclotron Rd., Berkeley, California 94720, United States. \\ $¥$ Joint Center for Artificial Photosynthesis and Division of Chemistry and Chemical \\ Engineering, California Institute of Technology, 1200 E. California Blvd., Pasadena, \\ California 91125, United States. \\ \#These authors contributed equally to this work.
}

\section{Corresponding Author}

*E-mail: wsdrisdell@1bl.gov; cxx@caltech.edu 


\begin{abstract}
The rational design of high-performance electrocatalysts requires a detailed understanding of dynamic changes in catalyst properties, including oxidation states, surface area, and morphology under realistic working conditions. Oxide-derived $\mathrm{Cu}$ catalysts exhibit a remarkable selectivity towards multi-carbon products for the electrochemical $\mathrm{CO}$ reduction reaction (CORR), but the exact role of oxide remains elusive for explaining the performance enhancements. Here, we used operando X-ray absorption spectroscopy (XAS) coupled with simultaneous measurements of catalyst activity and selectivity by gas chromatography (GC) to study the relationship between oxidation states of $\mathrm{Cu}$-based catalysts and activity for ethylene $\left(\mathrm{C}_{2} \mathrm{H}_{4}\right)$ production in a $\mathrm{CO}$ gas-fed cell. By utilizing a custom-built XAS cell, oxidation states of $\mathrm{Cu}$ catalysts can be probed in device-relevant settings and under high current densities $(>80$ $\mathrm{mA} / \mathrm{cm}^{-2}$ ) for CORR. By employing an electrochemical oxidation process, we found that the $\mathrm{Cu}$ oxidation states and specific ion species do not correlate with $\mathrm{C}_{2} \mathrm{H}_{4}$ production. The difference in CORR activity is also investigated in relation to the electrochemical surface area (ECSA) changes. While hydrogen evolution reaction (HER) activity is positively correlated to the ECSA changes, the increased $\mathrm{C}_{2} \mathrm{H}_{4}$ activity is not proportional to ECSA. Ex-situ characterization from microscopic techniques suggests that the changes in $\mathrm{C}_{2} \mathrm{H}_{4}$ activity and selectivity may arise from a morphological transformation that evolves into a more active structure. These comprehensive results give rise to the development of a cell regeneration method that can restore the performance of $\mathrm{Cu}$ catalyst without cell disassembly. Our study establishes a basis for the rational design of highly active electrocatalysts for broad-range reactions in a gas-fed device.
\end{abstract}

\title{
Keywords
}

operando X-ray absorption spectroscopy, electrochemical CO reduction, oxide-derived copper electrocatalyst, gas diffusion electrode, oxidation state 


\section{- INTRODUCTION}

The electrochemical reduction reactions of carbon monoxide (CORR) and carbon dioxide $\left(\mathrm{CO}_{2} \mathrm{RR}\right)$ are promising strategies to convert waste emissions into valuable chemical feedstocks, such as synthesis gas, hydrocarbons, and oxygenates. ${ }^{1-4}$ The CORR process is specifically interesting because it can be part of a tandem catalysis system, in which the first catalytic reaction converts $\mathrm{CO}_{2}$ into $\mathrm{CO}$, and the second catalytic reaction converts $\mathrm{CO}$ into higher-order reduction products such as ethanol or ethylene. ${ }^{5,6}$ By leveraging the efficient and selective first two-electron, two-proton process from $\mathrm{CO}_{2}$ to $\mathrm{CO}$, analysis shows that the optimal solar to fuel conversion efficiency of a tandem catalysis system was higher than that of the direct $\mathrm{CO}_{2} \mathrm{RR}$ system at all cathodic overpotential and Faradic Efficiency (FE) combinations. ${ }^{7}$ In the CORR process, copper-based materials are the only electrocatalysts that can produce more reduced hydrocarbons and oxygenates due to the optimal $\mathrm{Cu}-\mathrm{CO}$ binding strength. ${ }^{8,9}$ For lower activation overpotentials and increased FEs, Cu-based catalysts have been tuned via nanostructuring, ${ }^{10}$ modifying electrochemical surface area (ECSA), ${ }^{11}$ or the introduction of a second metal. ${ }^{12,13}$ In particular, oxide-derived $\mathrm{Cu}(\mathrm{OD}-\mathrm{Cu})$ prepared from the oxidative treatment of polycrystalline $\mathrm{Cu}$ resulted in high $\mathrm{CO}$ reduction selectivity toward multi-carbon oxygenates at modest potentials. ${ }^{14}$ Although the high $\mathrm{CO}$ reduction activity was correlated to surface sites that bind CO strongly, ${ }^{15,16}$ the detailed mechanism for catalytic enhancement and surface structure during CORR remains elusive.

To understand the origin of superior catalytic activity of $\mathrm{OD}-\mathrm{Cu}$ in comparison to polycrystalline $\mathrm{Cu}$, previous studies focused on structural transformations during the oxidation and subsequent in-situ reduction. ${ }^{17,18}$ This oxidation-reduction process increases surface roughness which can create high densities of grain-boundaries. ${ }^{19}$ The grain-boundary surface terminations showed a selective increase in $\mathrm{CO}_{2} \mathrm{RR}$ activity, but not for the parasitic HER. ${ }^{20}$ This observation triggered a detailed mechanistic question of whether the activity enhancement comes from an increase in the number of active surface sites or an increase in the intrinsic activity of a specific active site. An extensive effort for investigating the active site has concentrated on detecting $\mathrm{Cu}^{+}$and subsurface oxide under operation as theoretical calculations suggest that these species can improve the kinetics and thermodynamics of $\mathrm{CO}$ dimerization. ${ }^{21}$ The presence of $\mathrm{Cu}^{+}$and subsurface oxygen under highly reductive conditions was confirmed by microscopic and spectroscopic techniques, ${ }^{22,23}$ but most of these studies did not run the 
CORR or $\mathrm{CO}_{2} \mathrm{RR}$ so it is unclear if catalytic environments during the measurements are relevant to the actual catalytic reaction. The experiments also relied on ex-situ or quasi in-situ tools that cannot exclude possible rapid re-oxidation of OD-Cu before measurement. ${ }^{24,25}$ Moreover, in many studies of the highly active $\mathrm{Cu}$-based catalysts, the explanation for high performance depends on simple confirmation of $\mathrm{Cu}^{+}$or oxygen content, with no proof of whether they are involved in the catalytic reaction or not. These uncertainties hinder the development of general relationships between catalyst structure and activity.

In order to investigate oxidation states of $\mathrm{Cu}$ catalysts during CORR, previous studies utilized operando XAS cells that are modified from an existing high-performance cell design. ${ }^{26,27}$ These cells, however, typically operate at total current densities of up to $5 \mathrm{~mA} \mathrm{~cm}^{-2}$, much lower than operating conditions for catalyst performance measurements which can exceed 100 $\mathrm{mA} \mathrm{cm}{ }^{-2} .{ }^{28}$ The operando conditions are not necessarily representative because the surface of the catalyst and local environments are known to be very sensitive to changes in reaction rate and cell configurations. ${ }^{29}$ The structural information obtained in such controlled conditions often ignore $\mathrm{CO}$ mass transport limitations and may not represent the real oxidation states under practical operating conditions. Although the gas-diffusion layer (GDL)-based cell setup has been explored to overcome the mass transport limitations, ${ }^{30}$ a careful evaluation of CORR activity and selectivity in the modified operando cell is still needed to guarantee that the observed catalyst structure represents the real situation under operating conditions. ${ }^{31,32}$ By considering these circumstances, we set our research goals as follows. First, investigating the direct relationship between oxidation states and CORR performance using a well-configured operando XAS cell is required to understand the exact roles of oxide phases. Of particular interest is the oxidation state of a catalyst under high current densities without depletion of $\mathrm{CO}$ molecules. Second, determining if dynamic changes in catalyst surface area can influence $\mathrm{C}_{2+}$ selectivity and activity. Addressing these goals is required to formulate the general design principles for active CORR electrocatalysts.

Herein, we report a time-resolved operando study on the effect of oxidation states on CORR performance by XAS and online GC, which allows simultaneous monitoring of chemical valence state and product selectivity. We prepared three types of $\mathrm{Cu}$ catalysts with different oxidation states and introduced an electrochemical oxidation process, which enabled us to investigate the relationship between oxidation states and C-C coupling. By utilizing a modified 


\section{- RESULTS AND DISCUSSION}

Synthesis and CORR activity of Cu catalysts in an operando XAS cell. To determine the relationship between oxidation states and CORR performance, we carefully designed synthetic protocols to synthesize three catalysts with three different oxidation states of $\mathrm{Cu}$. The crystalline structure and morphology of the three as-prepared $\mathrm{Cu}$ catalysts were confirmed by $\mathrm{XRD}$ and SEM. The XRD analysis indicated that $\mathrm{Cu}_{2} \mathrm{O}-\mathrm{GDE}$ and CuO-GDE show good agreement with characteristic $\mathrm{Cu}_{2} \mathrm{O}$ and $\mathrm{CuO}$ peaks, respectively (Figure $\mathrm{S} 1$ ). The $\mathrm{Cu}-\mathrm{GDE}$ not only had peaks that matched with metallic $\mathrm{Cu}$ but also had a small amount of $\mathrm{Cu}_{2} \mathrm{O}$ due to spontaneous oxidation in ambient air. In SEM images, both the Cu-GDE and CuO-GDE show dendritic structures with sizes ranging from 5 10 $\mu \mathrm{m}$. Cu-GDE exhibited a sharper dendritic structure, while $\mathrm{CuO}-\mathrm{GDE}$ exhibited more rounded tips (Figures 1a and 1c). $\mathrm{The}^{\mathrm{Cu}_{2} \mathrm{O}-\mathrm{GDE}}$ exhibited a cubic-shaped morphology with a size of less than $10 \mu \mathrm{m}$ (Figure 1b).

For evaluating the electronic structure and oxidation states during the CORR, we used minimal modifications to an existing gas-fed cell, incorporating an X-ray transmissive window to accommodate operando XAS measurements (Figure S2). The gas-fed cell is based on a hybrid catalyst-bonded membrane device that exhibited total operating current density up to 87 $\mathrm{mA} \mathrm{cm}{ }^{-2}$ at $-2.0 \mathrm{~V}$ (vs. $\mathrm{Ag} / \mathrm{AgCl}$, hereafter all voltage is vs. $\mathrm{Ag} / \mathrm{AgCl}$ ). ${ }^{33} \mathrm{We}$ first characterized the CORR activity and selectivity of the Cu-GDE in the operando XAS cell to verify the effects of cell modification on the catalyst performance. The total current density reached $80 \mathrm{~mA} \mathrm{~cm}$ ${ }^{2}$ at $-2.2 \mathrm{~V}$, and its trend followed an exponential increase for the potential window of $-1.6 \mathrm{~V}$ to $-2.2 \mathrm{~V}$, demonstrating sufficient $\mathrm{CO}$ mass transport over these potential ranges (Figures S3a 
and $\mathrm{S} 3 \mathrm{~b}$ ). The $\mathrm{FE}$ for $\mathrm{C}_{2} \mathrm{H}_{4}$ and $\mathrm{H}_{2}$ generation reached $\sim 11 \%$ and $\sim 79 \%$ at $-2.2 \mathrm{~V}$, respectively. (Figure S3c). Compared to the CORR performance in the original gas-fed cell, we found slight differences in the calculated $\mathrm{FE}$ for $\mathrm{C}_{2} \mathrm{H}_{4}$ selectivity (decreased from $18 \%$ to $11 \%$ ), and for $\mathrm{H}_{2}$ (increased from $51 \%$ to $79 \%$ ) in the operando XAS cell. We ascribe these changes to the modified parts that may prevent the pressure buildup necessary to reduce water flooding (Figure S3d). ${ }^{34}$ However, the operando XAS cell maintained a similar total operating current densities $\left(\sim 80 \mathrm{~mA} \mathrm{~cm}^{-2}\right)$ compared to the original cell, which allowed us to observe actual states of catalyst structure under realistic operating conditions. During the operando XAS measurements, we were only able to detect gas products, including $\mathrm{H}_{2}$ and $\mathrm{C}_{2} \mathrm{H}_{4}$, because space constraints in the beamline hutch did not allow us to sample the liquid products in real-time. The corresponding operando $\mathrm{Cu}$ K-edge XAS was obtained after a potential hold of $1 \mathrm{hr}$. XANES analysis shows that the $\mathrm{Cu}-\mathrm{GDE}$ was metallic $\mathrm{Cu}^{0}$ after $1 \mathrm{hr}$ for all applied potentials except the potential at $-1.6 \mathrm{~V}$ (Figures S4a and S4b). EXAFS analysis indicates that all the samples have a prominent $\mathrm{Cu}-\mathrm{Cu}$ scattering peak at $2.2 \AA$ across a range of applied potentials, which is indicative of the metallic $\mathrm{Cu}^{0}$ phase. (Figure $\mathrm{S} 4 \mathrm{c}$ ). These data also demonstrated that performing operando XAS on Cu catalysts with different oxidation enables us to systemically validate the contribution of oxidation states to the CORR catalytic activity of Cu-based materials in the gas-fed cell.

Probing oxidation states of $\mathrm{Cu}$ catalysts by operando XAS. To investigate the $\mathrm{Cu}$ valence fraction in real-time during CORR, we performed time-resolved XAS measurements of three $\mathrm{Cu}$ catalysts under CORR operating conditions. We applied the potential of $-2.2 \mathrm{~V}$ because it exhibited the highest FE for ethylene generation. During the operando XAS measurements, gas products were characterized by using online $\mathrm{GC}$, and the $\mathrm{GC}$ and XAS measurements were synchronized such that both collected data every $6 \mathrm{~min}$. (Figure S5). Other gaseous products such as methane and ethane exhibited negligible FEs during the bulk electrolysis $(<0.2 \%)$. For quantitative analysis of the $\mathrm{Cu}$ oxidation states, linear combination fitting (LCF) was employed using a set of pure-valence references (Figure S6a). ${ }^{35}$ Compared to the reference spectra, the observed XANES spectra presented a lower amplitude due to the over-absorption effect (Figure S6b). All the spectra were corrected for over-absorption by using a simple model (Table S1). ${ }^{36}$ By using the synchronized measurements of GC and XAS with rigorous over-absorption 
correction and LCF, the operando XAS cell and analysis provide a useful platform to study the correlation between catalyst oxidation states and catalytic performance for CORR.

We tracked the change of XANES spectra for three $\mathrm{Cu}$ catalysts overtime under the fixed potential of -2.2 V (Figures 1d-f). Repeated XANES spectra were collected until no further changes were observed. In the case of $\mathrm{Cu}-\mathrm{GDE}$ and $\mathrm{Cu}_{2} \mathrm{O}-\mathrm{GDE}$, the $\mathrm{Cu}^{+}$reduced to metallic $\mathrm{Cu}^{0}$ within $20 \mathrm{~min}$, and the $\mathrm{C}_{2} \mathrm{H}_{4}$ production was detected in the first $\mathrm{GC}$ measurement at 6 min (Figures $1 \mathrm{~g}$ and $1 \mathrm{~h}$ ). Interestingly, $\mathrm{CuO}-\mathrm{GDE}$ exhibited no detectable $\mathrm{C}_{2} \mathrm{H}_{4}$ product until the $\mathrm{CuO}$ phase began to reduce to metallic $\mathrm{Cu}^{0}$ at 24 minutes (Figure 1i). The trend $\mathrm{C}_{2} \mathrm{H}_{4}$ partial current densities followed the evolution of the metallic $\mathrm{Cu}^{0}$ phase and showed the maximum value after reducing all the residual oxide into $\mathrm{Cu}^{0}$. This result suggests that $\mathrm{CuO}$ itself is inactive for the reduction reaction of $\mathrm{CO}$ molecules, and $\mathrm{C}-\mathrm{C}$ coupling occurs only at the $\mathrm{Cu}^{0}$ surface. Our observations were also in agreement with previously reported oxide-containing $\mathrm{Cu}$ catalysts that exhibited high $\mathrm{C}_{2} \mathrm{H}_{4}$ activity after a pre-activation step. ${ }^{30,37}$

It is important to note that all the $\mathrm{Cu}$ catalysts reduced to metallic $\mathrm{Cu}^{0}$ states during $\mathrm{CORR}$ regardless of its initial oxidation states. Although the LCF analysis of $\mathrm{Cu}_{2} \mathrm{O}-\mathrm{GDE}$ shows $\sim 3.7 \%$ of $\mathrm{Cu}^{+}$remaining in the $\mathrm{Cu}_{2} \mathrm{O}-\mathrm{GDE}$ after $30 \mathrm{~min}$, this amount of residual oxides is within the error range of LCF analysis. To estimate the error range in the LCF analysis, we introduced an empirical method by using normalized sum-squares (NSS) as a best-fit criterion (Figure S7). In this respect, we conclude that the accuracy for the determination of $\mathrm{Cu}$ oxidation states via LCF analysis is within 3-4\%.

Correlation between oxidation states and CORR performance. Previous studies have claimed efficient $\mathrm{C}-\mathrm{C}$ coupling during $\mathrm{CO}_{2} \mathrm{RR}$ from surface or subsurface $\mathrm{Cu}$ oxide species, which formed via an electrochemical oxidation process. ${ }^{18,38,39}$ During $\mathrm{CO}_{2} \mathrm{RR}$, the residual oxygen was mainly located in an amorphous 1-2 nm thick layer within the $\mathrm{Cu}$ subsurface. ${ }^{23}$ Accordingly, we aimed in the next step to investigate the effects of surface oxide species on CORR performance by applying an anodic potential to all the reduced $\mathrm{Cu}$ catalysts. The generation of the surface oxide structure was based on a previous study showing that copper oxide starts to grow at the surface at sufficient high positive potentials in alkaline solution. ${ }^{40} \mathrm{~A}$ highly positive potential of $1.5 \mathrm{~V}$ was applied for $5 \mathrm{~min}$ to the $\mathrm{Cu}$ catalysts that had already 
converted into metallic $\mathrm{Cu}^{0}$ states after the previous CORR. After the anodic oxidation, the XANES spectra show oxide features, and LCF analysis reveals that copper oxides and hydroxides were formed in all $\mathrm{Cu}$ catalysts up to $60 \%$ (Figures 2 and S8). We then performed operando XANES measurements and evaluated CORR performance simultaneously at the fixed potential of $-2.2 \mathrm{~V}$. Unlike the previous CORR results before the anodic oxidation (Figures $1 \mathrm{~g}-\mathrm{i}$ ), most of the surface oxide and hydroxide species in all $\mathrm{Cu}$ catalysts were quickly reduced into metallic $\mathrm{Cu}^{0}$ within the time resolution of the XANES measurement $(<6 \mathrm{~min})$ (Figures $2 \mathrm{a}$ and $\mathrm{S} 8$ ). The result suggests that the surface oxides are generally much easier to reduce than the initial oxides in the $\mathrm{Cu}$ catalysts. Moreover, similar features in the CORR selectivity and activity were observed through all the $\mathrm{Cu}$ catalysts. First, the total current densities of all the catalysts were increased after the anodic oxidation process, leading to significant enhancements of the partial current densities for both $\mathrm{C}_{2} \mathrm{H}_{4}$ and $\mathrm{H}_{2}$ (Figure S9). In comparison to that of initial $\mathrm{Cu}$ catalysts before anodic oxidation treatment, the $\mathrm{FE}_{\mathrm{C} 2 \mathrm{H} 4}$ was increased and $\mathrm{FE}_{\mathrm{H} 2}$ was decreased in all the $\mathrm{Cu}$ catalysts. Second, the enhanced partial current densities of $\mathrm{C}_{2} \mathrm{H}_{4}$ in all the $\mathrm{Cu}$ catalysts rapidly declined as CORR proceeded.

Interestingly, the $\mathrm{LCF}$ analysis of $\mathrm{Cu}_{2} \mathrm{O}$ - and $\mathrm{CuO}-\mathrm{GDE}$ demonstrates that residual oxide species ( $\sim 5 \%)$ remained after further reaction time (Figures $2 \mathrm{~b}$ and S8d). Although this amount of residual oxide is quite close to the error margins of the LCF analysis, its presence and persistence during reaction have been regarded as the promoter for $\mathrm{C}-\mathrm{C}$ coupling. ${ }^{24,41} \mathrm{We}$ hypothesize that there could be an optimal oxidation state value or a linear correlation between oxidation states and CORR performance if the residual oxide plays a role in the catalytic reaction. To verify this hypothesis and explore the relationship between oxidation states and CORR performance, we link the average oxidation number calculated from the LCF analysis and CORR activity (vs. $\mathrm{C}_{2} \mathrm{H}_{4}$ partial current density, Figure $2 \mathrm{c}$ ), and selectivity (vs. $\mathrm{FE}_{\mathrm{C} 2 \mathrm{H} 4 \text {, }}$ Figure $2 \mathrm{~d}$ ) before and after anodic oxidation process. However, the oxidation states show no apparent correlation with the activity or selectivity. The contribution of each $\mathrm{Cu}$ ion species, including $\mathrm{Cu}^{0}, \mathrm{Cu}^{+}$, and $\mathrm{Cu}^{2+}$ to CORR activity and selectivity was also investigated, but no obvious trend was observed (Figure S10). Although hard XAS measurements at the $\mathrm{Cu}$ K-edge contains bulk-sensitive information and the LCF analysis cannot exclude a possible existence of residual oxides lower than $4 \%$, this result is in contrast to the previous studies that utilized in-situ XAS cells. ${ }^{24,42}$ Our findings highlight the importance of catalyst performance evaluation 
in operando cell and direct linkage between observed XAS spectra and the catalyst performance measured simultaneously.

We also tested the steady-state $\mathrm{CV}$ cycling method to regenerate the surface oxide on the $\mathrm{Cu}$ catalyst. This mild oxidative-reductive process in alkaline solution has been used to induce step-wise reconstruction into a $\mathrm{Cu}(511)$ surface that catalyzes the conversion of $\mathrm{CO}$ molecules into ethanol. ${ }^{43}$ The $\mathrm{CV}$ cycling method with cycling potential between $-1.1 \mathrm{~V}$ and $0.5 \mathrm{~V}$ for 20 cycles was applied to the $\mathrm{Cu}-\mathrm{GDE}$ that was already reduced into metallic $\mathrm{Cu}^{0}$. The $\mathrm{CV}$ data indicates that $\mathrm{Cu}^{+}$was formed at $-0.4 \mathrm{~V}$, and $\mathrm{Cu}^{2+}$ was generated in the range of $0.05 \sim 0.25 \mathrm{~V}$, leading to the formation of oxidized copper (Figure $3 \mathrm{a}$ ). ${ }^{40}$ This formed oxide was reduced again between $-0.6 \mathrm{~V}$ and $-1 \mathrm{~V}$, as shown by the reductive wave in the $\mathrm{CV}$. Operando XANES demonstrated that there was no change in the spectra before and after CV cycling (Figure 3b), and LCF analysis confirmed that the two spectra indicate purely metallic $\mathrm{Cu}^{0}$ states (Figure 3c). In contrast, the $\mathrm{C}_{2} \mathrm{H}_{4}$ partial current densities were increased about 4 times higher than those before the $\mathrm{CV}$ cycling (Figure 3c), consistent with the results from the oxidative treatment method. This result further supports our conclusion that the oxidation states of $\mathrm{Cu}$ catalysts fail to explain the difference in the catalytic activity and selectivity for CORR in high current density operation $>80 \mathrm{~mA} \mathrm{~cm}^{-2}$.

The effects of electrochemical surface area on CORR. The lack of correlation between the oxidation state of $\mathrm{Cu}$ catalysts and CORR performance naturally points to another common factor, ECSA. It has been previously reported that the ECSA-normalized CORR activities of high and low surface area $\mathrm{Cu}$ are comparable, leading to the conclusion that both catalysts have similar intrinsic activity. ${ }^{44}$ The major difference in selectivity between these $\mathrm{Cu}$ catalysts was attributed to lower intrinsic HER activity in high ECSA catalysts due to local elevation of the $\mathrm{pH}$ from the rapid consumption of protons at high rates. ${ }^{11,45} \mathrm{We}$ investigated the role of ECSA on CORR performance enhancement to understand whether the electrochemical oxidation can simply increase the number of active sites, or create new, more efficient active sites. The ECSAs of all the $\mathrm{Cu}$ catalysts were estimated by measuring the electrochemical double-layer capacitance (EDLC, Figure S11), which has been used to estimate a proxy for wetted GDL electrode area in the gas-fed $\mathrm{CO}_{2}$ electrolyzers. ${ }^{46}$ Note that although the ECSA obtained by EDLC measurements could contain contributions from both $\mathrm{Cu}$ catalyst and GDL, our 
deposition method (detailed in the Experimental Section) is likely to cover the majority of the electrolyte-accessible portion of the GDL with the $\mathrm{Cu}$ catalyst. We therefore expect the EDLC measurements to provide a good approximation of the catalyst ECSA. The EDLC of the catalysts were measured at three periods before and after CORR, and after anodic oxidation in the gas-fed cell (Table S2). All the EDLC of Cu catalysts increased during CORR and slightly decreased after anodic oxidation. The increase in EDLC during CORR could arise from accelerating electrolyte ingress into the GDE. Such an increase in EDLC is consistent with a previous report that passage of Faradaic current leads to increasing apparent hydrophilicity of a GDL over time, resulting in water flooding. ${ }^{46}$ Also, we consistently observed salt crystallites on the catalyst layer in all the Cu catalysts (Figure S12). As salt crystallites form, they may draw water through the GDL via capillary force owing to their hygroscopic properties. ${ }^{47}$

Based on the above results, we measured partial current densities for $\mathrm{C}_{2} \mathrm{H}_{4}$ and $\mathrm{H}_{2}$ at the same points where the ECSAs were obtained (Figure S13), and linked them to the ECSA of Cu catalysts. We note that the total FEs of all the $\mathrm{Cu}$ catalysts were less than unity because liquid products were measured from the anode side of the gas-fed cell where oxidation of some products can occur. ${ }^{33}$ We observe that the ECSA value was positively correlated with $\mathrm{H}_{2}$ partial current density $\left(R^{2}=0.72\right.$, Figure $\left.4 a\right)$, suggesting that flooded electrolyte impeded the influx of CO gas to the catalyst surface and promoted HER. Such enhanced water flooding and a higher rate of HER was also observed in the operando XAS cell compared to that of the gasfed cell (Figure S14). These results highlight that the characterization of catalyst performance in the operando XAS cell is critical to guarantee the real operating condition of CORR. The ECSA-normalized partial current densities for $\mathrm{H}_{2}$ increased slightly or were similar before and after oxidation (Figure 4c), indicating that intrinsic activity for HER was not affected by the anodic oxidation process. In contrast, there was no linear correlation between ECSA and $\mathrm{C}_{2} \mathrm{H}_{4}$ partial current densities $\left(\mathrm{R}^{2}=0.39\right.$, Figure $\left.4 \mathrm{~b}\right)$, and the ECSA-normalized $\mathrm{C}_{2} \mathrm{H}_{4}$ current densities significantly increased after oxidation in all $\mathrm{Cu}$ catalysts (Figure $4 \mathrm{~d}$ ). Considering that wetted surfaces estimated by the EDLC values were slightly decreased after anodic oxidation, we explicitly exclude an increase in the number of active sites for the CORR from the reduction of pre-oxidized catalyst as a cause of increased activity in the gas-fed cell. Therefore, we conclude that the electrochemical oxidation increases $\mathrm{C}_{2} \mathrm{H}_{4}$ activity and selectivity by generating new, highly selective active sites for C-C coupling. 
The morphological transformation of $\mathrm{Cu}$ catalysts during CORR. Our observation that neither oxidation state nor ECSA are correlated with activity and selectivity suggests another catalyst property determining CORR performance in gas-fed cells. Since Cu has small cohesive energy and high surface mobility, the surface of $\mathrm{Cu}$ undergoes severe reconstruction when exposed to gaseous $\mathrm{CO}^{48}$ or under the CORR conditions. ${ }^{49}$ In particular, the adsorption of $\mathrm{CO}$ into oxide-containing $\mathrm{Cu}$ catalysts invokes a surface reconstruction in the form of nanoclusters or fragmented structures that resulted in enhanced n-propanol production during CORR. ${ }^{30,37}$ This CO-induced surface reconstruction motivates us to investigate the relationship between morphological changes and the CORR performance of our $\mathrm{Cu}$ catalysts. To investigate the morphological evolution during CORR, we collected post-mortem SEM (Figures 5a-c) and TEM (Figures 5d-f) images of $\mathrm{Cu}-\mathrm{GDE}$ before and after electrolysis and the electrochemical oxidation. The dendritic structure in the pristine $\mathrm{Cu}-\mathrm{GDE}$ was composed of nanocubes with a size ranging from 100 150 nm (Figure 5a) and a crystalline surface layer (Figure 5d). The fast Fourier transform (FFT) pattern of the nanocube showed $\mathrm{Cu}_{2} \mathrm{O}(111)$ and (110) phases, but additional $\mathrm{CuO}$ phase patterns were also observed due to surface oxidation in the ambient conditions during ex-situ TEM analysis (Figure S15). After the initial CORR proceeded for 60 min, the nanocubes were no longer observed, having coalesced into a smooth surface (Figure 5b). The TEM image showed that the crystalline surface was still maintained even after CORR (Figure 5e). This result is in agreement with a degradation mechanism induced by either H- or CO-adsorbates under highly negative potentials. ${ }^{50}$ After applying a positive potential of $1.5 \mathrm{~V}$ for $5 \mathrm{~min}$, the $\mathrm{Cu}$ surfaces became covered with nanoparticles ranging in size from $50 \sim 80 \mathrm{~nm}$ (Figure $5 \mathrm{c}$ ). The nanoparticles had an amorphous surface structure resulting from anodic oxidation treatment (Figure 5f). As the second period of CORR proceeded, the newly formed nanoparticles also coalesced into a flat and smooth surface (Figure S16). A similar trend of coalescence during CORR and subsequent formation of nanoparticles during anodic oxidation was also observed for both $\mathrm{Cu}_{2} \mathrm{O}$ - and CuO-GDE (Figure S17), suggesting the generality of this morphological transformation irrespective of initial oxidation states and morphology.

This finding suggests a hypothesis regarding the catalyst properties that determine CORR activity and selectivity in the gas-fed cell. At the early stage of the electrolysis, lower wetted surface area and larger particle size compared to those after anodic oxidation are likely to hinder the generation of $\mathrm{Cu}$ active sites by restricting the morphological transformation of the 
catalysts. Moreover, the coalescence of nanostructures into smooth surfaces as CORR proceeds can also limit the availability of active sites during CORR, leading to a decrease of $\mathrm{C}_{2} \mathrm{H}_{4}$ partial current densities as a function of time in all $\mathrm{Cu}$ catalysts. After anodic oxidation, the enhancements of $\mathrm{C}_{2} \mathrm{H}_{4}$ activity and selectivity may result from the formation of oxide nanoparticles at the surface and their rapid reduction that could create a more active $\mathrm{Cu}$ structure. A reconstructed $\mathrm{Cu}$ structure is consistent with previous studies demonstrating that the electrochemical oxidative-reductive process generates selective active sites for $\mathrm{C}-\mathrm{C}$ coupling. ${ }^{43,51}$ While we cannot rule out a small fraction of oxidized $\mathrm{Cu}$ below the error range of our LCF analysis, these post-mortem measurements suggest that control over the morphological transformation during catalysis may be a key parameter for achieving high catalytic activities in a practical $\mathrm{CO}$ electrolyzer.

Restoration of cell performance by electrochemical oxidation. Inspired by the above results, we explored the possibility of restoring cell performance through the anodic oxidation process. We first measured the gaseous and liquid products before and after oxidation in the gas-fed cell (Figure S17). Remarkably, we note that applying $0.1 \mathrm{~V}$ during the oxidative step was enough to enhance the $\mathrm{C}_{2} \mathrm{H}_{4}$ activity, and only $\mathrm{FE}_{\mathrm{C} 2 \mathrm{H} 4}$ was enhanced while other $\mathrm{C}_{2+}$ products remained similar after anodic oxidation (Table $\mathrm{S} 3$ ). The $\mathrm{C}_{2} \mathrm{H}_{4}$ partial current densities rapidly decreased over 30 min after the anodic oxidation, suggesting that the active sites are unstable under high reaction rates with large overpotentials. We hypothesize that the anodic oxidation can regenerate the stepped $\mathrm{Cu}$ active sites from the sintered $\mathrm{Cu}$ surface, making it possible to recover the activity periodically without any cell disassembly. To this end, we operated the gas-fed cell at the fixed potential of $-2.2 \mathrm{~V}$ for $1 \mathrm{~h}$ before applying $0.1 \mathrm{~V}$ for $5 \mathrm{~min}$, followed by alternating $30 \mathrm{~min}$ at $-2.2 \mathrm{~V}$ and $5 \mathrm{~min}$ at $0.1 \mathrm{~V}$ (Figure 6). The first anodic oxidation increased CORR activity (from 15.7 to $28.4 \mathrm{~mA} \mathrm{~cm}^{-2}$ ) and selectivity (16.8 to $28.4 \%$ ) toward $\mathrm{C}_{2} \mathrm{H}_{4}$ and suppressed $\mathrm{H}_{2}$ production, while the enhanced performance degraded over $30 \mathrm{~min}$. Subsequent anodic oxidation cycles showed repeated degradation and recovery of $\mathrm{C}_{2} \mathrm{H}_{4}$ current density. During this periodic cycling, the initial current density and $\mathrm{FE}$ for $\mathrm{C}_{2} \mathrm{H}_{4}$ were maintained even after $6 \mathrm{hr}$. However, both the current density and $\mathrm{FE}$ for $\mathrm{H}_{2}$ increased over time. Previous studies showed that this was due to electrolyte crossover from the anode chamber which limited $\mathrm{CO}$ transport to the flooded catalyst layer, indicating that water management is important to 
suppress $\mathrm{H}_{2}$ production in gas-fed cells. ${ }^{33,46}$ To suppress parasitic HER, strategies for water management include integrating hydrophobic materials (for example, polytetrafluoroethylene) into the GDL and controlling the porous structure of both the catalyst layer and the GDL. ${ }^{34}$ Compared to the previous studies that include cell disassembly to restore the performance, ${ }^{52,53}$ in-situ regeneration by periodic anodic oxidation can provide a practical strategy to mitigate gas-fed GDE cell degradation.

\section{- CONCLUSION}

In conclusion, the effect of the oxidation state on the CORR activity of oxide-derived $\mathrm{Cu}$ catalysts was investigated by using simultaneous operando XAS and online GC measurements. Combining data from XANES fitting and synchronized product analysis, we found that the $\mathrm{C}_{2} \mathrm{H}_{4}$ activity and selectivity increased as the oxides were reduced to metallic $\mathrm{Cu}^{0}$. By introducing an electrochemical oxidation process, which improved CORR performance, we successfully proved that the oxidation states and specific ion species do not correlate with the activity or selectivity of $\mathrm{Cu}$ catalysts. Moreover, activities normalized by ECSA revealed that $\mathrm{H}_{2}$ production was proportional to the ECSA, while the conversion of $\mathrm{CO}$ into $\mathrm{C}_{2} \mathrm{H}_{4}$ was not affected by the ECSA in the gas-fed cell. We also demonstrated that modification of the cell design to include an X-ray window for the operando study could change the reaction environment, which indicates the importance of performance characterization in the operando cell. Post-mortem microscopic investigations of morphological changes suggest that the electrochemical oxidation and its subsequent reduction may generate a more active $\mathrm{Cu}$ structure surpassing the original activity. This electrochemical oxidation-reduction process was utilized as a regeneration method that restored the original catalyst activity and selectivity in the GDE cell without requiring cell disassembly. Based on our comprehensive study, we believe that our results motivate the rational design of catalysts for commercial $\mathrm{CO}$ reduction systems.

\section{- EXPERIMENTAL SECTION}

Synthesis of $\mathrm{Cu}$ catalysts with different oxidation states. $\mathrm{Cu}$ was electrodeposited on graphite-based GDLs (denoted as Cu-GDE, Sigracet, 39AA) in an electrolyte containing 0.15 
$\mathrm{M} \mathrm{CuCl}_{2} \cdot 2 \mathrm{H}_{2} \mathrm{O}$ (99.99\%, Alfa Aeasar), $1 \mathrm{M} \mathrm{HCl}$ (37\% ACS Grade, Sigma Aldrich), and 20\% ethanol (Koptek, 200 proof). Preferential deposition of $\mathrm{Cu}$ on one side of the GDL was achieved by applying polyimide tape (Kapton) to one side of the GDL and immersing in the electrolyte bath. The cell consisted of the GDL as a working electrode, $\mathrm{Cu}$ mesh as a counter electrode, and $\mathrm{Ag} / \mathrm{AgCl}$ (sat. $\mathrm{KCl}$ ) as a reference electrode. $-0.5 \mathrm{~V}$ vs. $\mathrm{Ag} / \mathrm{AgCl}$ was applied for a total charge of $4.5 \mathrm{C} / \mathrm{cm}^{2}$. After deposition, the resulting $\mathrm{Cu}-\mathrm{GDE}$ was taken out of solution and dipped in deionized water several times to rinse excess electrolyte. After rinsing, the Kapton tape was removed from the backside, and the electrode was dried in air. $\mathrm{Cu}_{2} \mathrm{O}$ was also electrodeposited on GDLs (denoted as $\mathrm{Cu}_{2} \mathrm{O}-\mathrm{GDE}$, Sigracet, 39AA) in an aqueous electrolyte containing 0.2 $\mathrm{M} \mathrm{CuSO}_{4}$ and 3.0 $\mathrm{M}$ lactic acid. The $\mathrm{pH}$ was adjusted to 12 , using a concentrated $\mathrm{NaOH}$ solution. Depositions were performed in a 3-electrode configuration using the GDL as a working electrode, $\mathrm{Pt}$ coil as a counter electrode, and $\mathrm{Ag} / \mathrm{AgCl}$ (sat. $\mathrm{KCl}$ ) as a reference electrode. $-0.5 \mathrm{~mA} / \mathrm{cm}^{2}$ was applied to the working electrode for $1.1 \mathrm{~h}$ at $60{ }^{\circ} \mathrm{C}$. The rinsing process was the same as that of $\mathrm{Cu}-\mathrm{GDE}$. To fabricate the $\mathrm{CuO}$ on the GDL, Cu-GDEs were electrodeposited as above, followed by oxidization in the air at $350{ }^{\circ} \mathrm{C}$ for $16 \mathrm{~h}$ in a muffle furnace (denoted as $\mathrm{CuO}-\mathrm{GDE}$ ).

Characterization. A scanning electron microscope (SEM, FEI Inc., NOVA NanoSEM 450) with an integrated energy-dispersive X-ray (EDX) spectrometer was used to analyze the morphology and elemental composition, respectively. Images were taken using an accelerating voltage of $15 \mathrm{kV}$. EDX images were taken with an accelerating voltage of $15 \mathrm{kV}$. X-ray diffraction (XRD) measurements were taken with a Bruker D8 Discover X-ray diffractometer using $\mathrm{Cu} \mathrm{K \alpha}$ radiation (1.54056 $\AA$ ) in Bragg-Brentano geometry. Diffraction images were collected using a two-dimensional VÅNTEC-500 detector and integrated into one-dimensional patterns using DIFFRAC.SUITETM EVA software. Transmission electron microscopy (TEM) was performed using an F20 UT Tecnai (FEI) microscope at an acceleration voltage of $200 \mathrm{kV}$.

Electrochemical Measurements. Electrochemical measurements were performed using a Biologic SP-300 model potentiostat. The GDE served as a working electrode, Pt mesh as a counter electrode, and $\mathrm{Ag} / \mathrm{AgCl}$ (sat. $\mathrm{KCl}$ ) as a reference electrode. The custom GDE cell 
consisted of two plates that sandwiched the $\mathrm{Cu} / \mathrm{Cu}_{2} \mathrm{O} / \mathrm{CuO}-\mathrm{GDE}$, anion exchange membrane (FAA-3-50, Fumatech), and Pt mesh anode and was tightened with external screws. 1.0 M $\mathrm{KOH}$ was circulated through the anode chamber, which also contained the reference electrode, as described earlier. ${ }^{33}$ All measurements were performed at room temperature $\left(25^{\circ} \mathrm{C}\right)$ and pressure (1 atm). The GDE cell was allowed to equilibrate at OCV conditions until the OCV measured $-1.0 \mathrm{~V}$, typically $1 \mathrm{~h}$. EIS measurements were taken at OCV conditions using a range of frequencies of $1 \mathrm{MHz}$ to $0.5 \mathrm{~Hz}$ and an amplitude of $10 \mathrm{mV}$.

Product analysis. Gas products were measured with online gas chromatography (GC, customized SRI instruments Model 8610C) every 6 min. A thermal conductivity detector (TCD) was used to detect $\mathrm{H}_{2}$, while a flame ionization detector (FID) was used to detect $\mathrm{CH}_{4}, \mathrm{C}_{2} \mathrm{H}_{4}$, and $\mathrm{C}_{2} \mathrm{H}_{6}$ products. A parallel column configuration was employed using a Molsieve $5 \mathrm{~A}$ column for $\mathrm{H}_{2}, \mathrm{O}_{2}, \mathrm{~N}_{2}$, and $\mathrm{CO}$ separation, and a Haysep D column to separate $\mathrm{CH}_{4}, \mathrm{CO}, \mathrm{CO}_{2}$, $\mathrm{C}_{2} \mathrm{H}_{4}$, and $\mathrm{C}_{2} \mathrm{H}_{6}$. An isothermal method was used with an oven temperature of $110{ }^{\circ} \mathrm{C}$, TCD temperature $105^{\circ} \mathrm{C}$, FID temperature $100{ }^{\circ} \mathrm{C}$, injection valve $60{ }^{\circ} \mathrm{C}$. Ar carrier gas was set to $20 \mathrm{psi}, \mathrm{H}_{2}$ methanizer gas set to $20 \mathrm{psi}$, and air pump set to $5 \mathrm{psi}$. Liquid products were analyzed from the anode side of the cell with high-performance liquid chromatography (HPLC, Dionex UltiMate 3000). The eluent was $1 \mathrm{mM} \mathrm{H}_{2} \mathrm{SO}_{4}$ in water with a flow rate of $0.6 \mathrm{ml} / \mathrm{min}$ and a column pressure of 76 bar. The column was an Aminex HPX 87- $\mathrm{H}$ from Biorad, held at $60{ }^{\circ} \mathrm{C}$ with an internal heater. The detector was a UV detector set to $250 \mathrm{~nm}$. Injection volume was $10 \mu \mathrm{L}$. For the determination of liquid products over time, $0.5 \mathrm{~mL}$ of anolyte was taken from the anolyte reservoir every $6 \mathrm{~min}$, in conjunction with GC measurements. The Faradaic efficiency (FE) was calculated as follows: $\mathrm{FE}=\mathrm{e} \times \mathrm{F} \times \mathrm{n} / \mathrm{Q}=\mathrm{e} \times \mathrm{F} \times \mathrm{n} /(\mathrm{I} \times \mathrm{t})$, where $\mathrm{e}$ is the number of electrons transferred, $\mathrm{F}$ is the Faraday constant, $\mathrm{Q}$ is the charge, $\mathrm{I}$ is current, $\mathrm{t}$ is the running time, and $\mathrm{n}$ is the total amount of product (in moles).

Operando X-ray absorption spectroscopy and data analysis. Operando X-ray absorption spectroscopy (XAS) measurements were conducted at the Stanford Synchrotron Radiation Lightsource (SSRL) on beamline 7-3 at the $\mathrm{Cu}$ K-edge. The operando experiments were performed under $\mathrm{CO}$ gas conditions using a GDE cell setup identical to the one used for 
evaluating CORR, ${ }^{33}$ with the slight modification of a polyimide (Kapton) window to allow for X-ray penetration on the vapor side, with the cell positioned at $45^{\circ}$ from the incident X-ray beam. The X-ray energy was tuned by a-Si (220) double-crystal monochromator, and the intensity of the incident X-rays $\left(I_{0}\right)$ was monitored by an Ar-filled ion chamber in front of the GDE cell. Data were collected as fluorescence excitation spectra at room temperature using a Ge 30 element detector (Canberra). Data analysis of $\mathrm{Cu}$ K-edge X-ray absorption near-edge spectroscopy (XANES) and extended X-ray absorption fine structure (EXAFS) spectra was performed using the Athena software package. ${ }^{54}$ Pre-edge and post-edge backgrounds were subtracted from the XAS spectra, and the resulting spectra were normalized by edge height. For the EXAFS spectra, three consecutive scans were averaged to increase the signal-to-noise ratio, and data reduction was performed with the Athena software. The procedures used for over-absorption correction and linear combination fitting (LCF) analysis are described in detail in the Supporting information.

Electrochemical oxidation. Potentiostatic electrochemical oxidation of the GDE films was performed by applying $1.5 \mathrm{~V}$ or $0.1 \mathrm{~V}$ for $5 \mathrm{~min}$ after bulk electrolysis $(-2.2 \mathrm{~V}, 1 \mathrm{~h})$. After 5 min of oxidation, the cell was allowed to equilibrate at OCV for $1 \mathrm{~min}$, followed by second bulk electrolysis at $-2.2 \mathrm{~V}$. Cyclic voltammetry (CV) was performed from $-1.1 \mathrm{~V}$ to $0.5 \mathrm{~V}$ at a scan rate of $50 \mathrm{mVs}^{-1}$ for 20 cycles, with the scan ending at $0.5 \mathrm{~V}$.

Electrochemical active surface area (ECSA) measurements. The electrochemically active surface area (ECSA) was determined from the double-layer capacitance of the films in a nonFaradaic potential range, typically $\pm 50 \mathrm{mV}$ of the open-circuit voltage (OCV). CV scans were performed at scan rates of $10,20,50,100$, and $200 \mathrm{mVs}^{-1}$ with the potential held at each vertex for $10 \mathrm{~s}$ before the next scan. The double-layer capacitance $\left(C_{d l}\right)$ is given by the equation

$$
i_{c}=v C_{d l}
$$

Where $i_{c}$ is the charging current $(\mathrm{mA})$, and $v$ is the scan rate $(\mathrm{V} / \mathrm{s})$. Charging current was plotted as a function of scan rate, with the slope equal to $C_{d l}$. The ECSA was then calculated using the equation 


$$
\operatorname{ECSA}=\frac{C_{d l}}{C_{S}}
$$

Where $C_{S}$ is the electrolyte dependent solution capacitance. We chose to assume a $C_{S}$ value of $0.04 \mathrm{mF} \mathrm{cm}^{-2}$ as previously described. ${ }^{55}$

\section{- AUTHOR INFORMATION}

\section{Corresponding authors}

*E-mail: wsdrisdell@1bl.gov; cxx@caltech.edu

\section{Author contributions}

${ }^{\#}$ S.H.L. and I.S. equally contributed to this work.

\section{Notes}

The authors declare no competing financial interests.

\section{ASSOCIATED CONTENT}

\section{Supporting Information}

Sample characterizations (XRD) as well as the electrochemical measurements (electroactive surface area, Faradaic efficiencies for all products) and XAS analysis are provided in the Supplementary Information. The Supporting Information is available free of charge via the Internet at http://pubs.acs.org

\section{ACKNOWLEDGMENTS}

This material is based on work performed by the Joint Center for Artificial Photosynthesis, a DOE Energy Innovation Hub, supported through the Office of Science of the U.S. Department of Energy under Award Number DE-SC0004993. Use of the Stanford Synchrotron Radiation Lightsource, SLAC National Accelerator Laboratory, is supported by the U.S. Department of Energy, Office of Science, Office of Basic Energy Sciences under Contract No. DE-AC02$76 \mathrm{SF} 00515$.

\section{- REFERENCES}

(1) De Luna, P.; Hahn, C.; Higgins, D.; Jaffer, S. A.; Jaramillo, T. F.; Sargent, E. H. What 
would it take for renewably powered electrosynthesis to displace petrochemical processes? Science 2019, 364, eaav3506.

(2) Singh, M. R.; Bell, A. T. Design of an artificial photosynthetic system for production of alcohols in high concentration from $\mathrm{CO}_{2}$. Energy Environ. Sci. 2016, 9, 193-199.

(3) Francis, S. A.; Velazquez, J. M.; Ferrer, I. M.; Torelli, D. A.; Guevarra, D.; McDowell, M. T.; Sun, K.; Zhou, X.; Saadi, F. H.; John, J.; Richter, M. H.; Hyler, F. P.; Papadantonakis, K. M.; Brunschwig, B. S.; Lewis, N. S. Reduction of Aqueous $\mathrm{CO}_{2}$ to 1Propanol at $\mathrm{MoS}_{2}$ Electrodes. Chem. Mater. 2018, 30, 4902-4908.

(4) Ross, M. B.; De Luna, P.; Li, Y.; Dinh, C.-T.; Kim, D.; Yang, P.; Sargent, E. H. Designing materials for electrochemical carbon dioxide recycling. Nat. Catal. 2019, 2, 648-658.

(5) Lum, Y.; Ager, J. W., Sequential catalysis controls selectivity in electrochemical $\mathrm{CO}_{2}$ reduction on Cu. Energy Environ. Sci. 2018, 11 (10), 2935-2944.

(6) Han, L.; Zhou, W.; Xiang, C., High-Rate Electrochemical Reduction of Carbon Monoxide to Ethylene Using Cu-Nanoparticle-Based Gas Diffusion Electrodes. $A C S$ Energy Lett. 2018, 3 (4), 855-860.

(7) Zhou, X.; Xiang, C., Comparative Analysis of Solar-to-Fuel Conversion Efficiency: A Direct, One-Step Electrochemical CO2 Reduction Reactor versus a Two-Step, Cascade Electrochemical $\mathrm{CO}_{2}$ Reduction Reactor. ACS Energy Lett. 2018, 3 (8), 1892-1897.

(8) Hori, Y.; Takahashi, R.; Yoshinami, Y.; Murata, A. Electrochemical Reduction of CO at a Copper Electrode. J. Phys. Chem. B 1997, 101, 7075-7081.

(9) Peterson, A. A.; Abild-Pedersen, F.; Studt, F.; Rossmeisl, J.; Nørskov, J. K. How copper catalyzes the electroreduction of carbon dioxide into hydrocarbon fuels. Energy Environ. Sci. 2010, 3, 1311-1315.

(10) Hoang, T. T. H.; Verma, S.; Ma, S.; Fister, T. T.; Timoshenko, J.; Frenkel, A. I.; Kenis, P. J. A.; Gewirth, A. A. Nanoporous Copper-Silver Alloys by Additive-Controlled Electrodeposition for the Selective Electroreduction of $\mathrm{CO}_{2}$ to Ethylene and Ethanol $J$. Am. Chem. Soc. 2018, 140, 5791-5797.

(11) Wang, L.; Nitopi, S.; Wong, A. B.; Snider, J. L.; Nielander, A. C.; Morales-Guio, C. G.; Orazov, M.; Higgins, D. C.; Hahn, C.; Jaramillo, T. F. Electrochemically converting carbon monoxide to liquid fuels by directing selectivity with electrode surface area. Nat. Catal. 2019, 2, 702-708.

(12) Ma, S.; Sadakiyo, M.; Heima, M.; Luo, R.; Haasch, R. T.; Gold, J. I.; Yamauchi, M.; 
Kenis, P. J. A. Electroreduction of Carbon Dioxide to Hydrocarbons Using Bimetallic $\mathrm{Cu}-\mathrm{Pd}$ Catalysts with Different Mixing Patterns. J. Am. Chem. Soc. 2017, 139, 47-50.

(13) Perryman, J. T.; Ortiz-Rodríguez, J. C.; Jude, J. W.; Hyler, F. P.; Davis, R. C.; Mehta, A.; Kulkarni, A. R.; Patridge, C. J.; Velázquez, J. M. Metal-promoted $\mathrm{Mo}_{6} \mathrm{~S}_{8}$ clusters: a platform for probing ensemble effects on the electrochemical conversion of $\mathrm{CO}_{2}$ and $\mathrm{CO}$ to methanol. Mater. Horiz. 2020, 7, 193-202.

(14) Li, C. W.; Ciston, J.; Kanan, M. W. Electroreduction of carbon monoxide to liquid fuel on oxide-derived nanocrystalline copper. Nature 2014, 508, 504-507.

(15) Verdaguer-Casadevall, A.; Li, C. W.; Johansson, T. P.; Scott, S. B.; McKeown, J. T.; Kumar, M.; Stephens, I. E. L.; Kanan, M. W.; Chorkendorff, I. Probing the Active Surface Sites for CO Reduction on Oxide-Derived Copper Electrocatalysts. J. Am. Chem. Soc. 2015, 137, 9808-9811.

(16) Jiang, K.; Huang, Y.; Zeng, G.; Toma, F. M.; Goddard, W. A.; Bell, A. T. Production of $\mathrm{C}_{2} / \mathrm{C}_{3}$ Oxygenates from Planar Copper Nitride-Derived Mesoporous Copper via Electrochemical Reduction of $\mathrm{CO}_{2}$. ACS Energy Lett. 2020, 5 (4), 1206-1214.

(17) Lum, Y.; Ager, J. W. Stability of Residual Oxides in Oxide-Derived Copper Catalysts for Electrochemical $\mathrm{CO}_{2}$ Reduction Investigated with ${ }^{18} \mathrm{O}$ Labeling. Angew. Chem. Int. Ed. 2018, 57, 551-554.

(18) Lum, Y.; Yue, B.; Lobaccaro, P.; Bell, A. T.; Ager, J. W. Optimizing C-C Coupling on Oxide-Derived Copper Catalysts for Electrochemical $\mathrm{CO}_{2}$ Reduction. J. Phys. Chem. C 2017, 121, 14191-14203.

(19) Feng, X.; Jiang, K.; Fan, S.; Kanan, M. W. A Direct Grain-Boundary-Activity Correlation for CO Electroreduction on Cu Nanoparticles. ACS Cent. Sci. 2016, 2, 169 174.

(20) Mariano, R. G.; McKelvey, K.; White, H. S.; Kanan, M. W. Selective increase in $\mathrm{CO}_{2}$ electroreduction activity at grain-boundary surface terminations. Science 2017, 358, 1187-1192.

(21) Xiao, H.; Goddard, W. A.; Cheng, T.; Liu, Y. Cu metal embedded in oxidized matrix catalyst to promote $\mathrm{CO}_{2}$ activation and $\mathrm{CO}$ dimerization for electrochemical reduction of $\mathrm{CO}_{2}$. Proc. Natl. Acad. Sci. U. S. A. 2017, 114, 6685-6688.

(22) Favaro, M.; Xiao, H.; Cheng, T.; Goddard, W. A.; Yano, J.; Crumlin, E. J. Subsurface oxide plays a critical role in $\mathrm{CO}_{2}$ activation by $\mathrm{Cu}(111)$ surfaces to form chemisorbed 
$\mathrm{CO}_{2}$, the first step in reduction of $\mathrm{CO}_{2}$. Proc. Natl. Acad. Sci. U. S. A. 2017, 114, 67066711.

(23) Eilert, A.; Cavalca, F.; Roberts, F. S.; Osterwalder, J.; Liu, C.; Favaro, M.; Crumlin, E. J.; Ogasawara, H.; Friebel, D.; Pettersson, L. G. M.; Nilsson, A. Subsurface Oxygen in Oxide-Derived Copper Electrocatalysts for Carbon Dioxide Reduction. J. Phys. Chem. Lett. 2017, 8, 285-290.

(24) Mistry, H.; Varela, A. S.; Bonifacio, C. S.; Zegkinoglou, I.; Sinev, I.; Choi, Y.-W.; Kisslinger, K.; Stach, E. A.; Yang, J. C.; Strasser, P.; Cuenya, B. R. Highly selective plasma-activated copper catalysts for carbon dioxide reduction to ethylene. Nat. Commun. 2016, 7, 12123.

(25) Gao, D.; Zegkinoglou, I.; Divins, N. J.; Scholten, F.; Sinev, I.; Grosse, P.; Roldan Cuenya, B. Plasma-Activated Copper Nanocube Catalysts for Efficient Carbon Dioxide Electroreduction to Hydrocarbons and Alcohols. ACS Nano 2017, 11, 4825-4831.

(26) Chan, C. K.; Tüysüz, H.; Braun, A.; Ranjan, C.; La Mantia, F.; Miller, B. K.; Zhang, L.; Crozier, P. A.; Haber, J. A.; Gregoire, J. M.; Park, H. S.; Batchellor, A. S.; Trotochaud, L.; Boettcher, S. W. Advanced and In Situ Analytical Methods for Solar Fuel Materials. In Solar Energy for Fuels; Tüysüz, H., Chan, C. K., Eds. Springer International Publishing: Cham, 2016; pp 253-324.

(27) De Luna, P.; Quintero-Bermudez, R.; Dinh, C.-T.; Ross, M. B.; Bushuyev, O. S.; Todorović, P.; Regier, T.; Kelley, S. O.; Yang, P.; Sargent, E. H. Catalyst electroredeposition controls morphology and oxidation state for selective carbon dioxide reduction. Nat. Catal. 2018, 1, 103-110.

(28) Jouny, M.; Luc, W.; Jiao, F. High-rate electroreduction of carbon monoxide to multicarbon products. Nat. Catal. 2018, 1, 748-755.

(29) Burdyny, T.; Smith, W. A. $\mathrm{CO}_{2}$ reduction on gas-diffusion electrodes and why catalytic performance must be assessed at commercially-relevant conditions. Energy Environ. Sci. 2019, 12, 1442-1453.

(30) Li, J.; Che, F.; Pang, Y.; Zou, C.; Howe, J. Y.; Burdyny, T.; Edwards, J. P.; Wang, Y.; Li, F.; Wang, Z.; De Luna, P.; Dinh, C.-T.; Zhuang, T.-T.; Saidaminov, M. I.; Cheng, S.; Wu, T.; Finfrock, Y. Z.; Ma, L.; Hsieh, S.-H.; Liu, Y.-S.; Botton, G. A.; Pong, W.-F.; Du, X.; Guo, J.; Sham, T.-K.; Sargent, E. H.; Sinton, D. Copper adparticle enabled selective electrosynthesis of n-propanol. Nat. Commun. 2018, 9, 4614. 
(31) Kondrat, S. A.; van Bokhoven, J. A. A Perspective on Counting Catalytic Active Sites and Rates of Reaction Using X-Ray Spectroscopy. Topics in Catalysis 2019, 62, 1218 1227.

(32) Newton, M. A.; Knorpp, A. J.; Pinar, A. B.; Sushkevich, V. L.; Palagin, D.; van Bokhoven, J. A. On the Mechanism Underlying the Direct Conversion of Methane to Methanol by Copper Hosted in Zeolites; Braiding $\mathrm{Cu}$ K-Edge XANES and Reactivity Studies. J. Am. Chem. Soc. 2018, 140, 10090-10093.

(33) Sullivan, I.; Han, L.; Lee, S. H.; Lin, M.; Larson, D. M.; Drisdell, W. S.; Xiang, C. A Hybrid Catalyst-Bonded Membrane Device for Electrochemical Carbon Monoxide Reduction at Different Relative Humidities. ACS Sustainable Chem. Eng. 2019, 7, 16964-16970.

(34) Li, H.; Tang, Y.; Wang, Z.; Shi, Z.; Wu, S.; Song, D.; Zhang, J.; Fatih, K.; Zhang, J.; Wang, H.; Liu, Z.; Abouatallah, R.; Mazza, A. A review of water flooding issues in the proton exchange membrane fuel cell. J. Power Sources 2008, 178, 103-117.

(35) Manceau, A.; Marcus, M. A.; Grangeon, S. Determination of Mn valence states in mixed-valent manganates by XANES spectroscopy. Am. Mineral. 2012, 97, 816-827.

(36) Manceau, A.; Marcus, M. A.; Tamura, N. Quantitative Speciation of Heavy Metals in Soils and Sediments by Synchrotron X-ray Techniques. Rev. Mineral. Geochem. 2002, 49, 341-428.

(37) Pang, Y.; Li, J.; Wang, Z.; Tan, C.-S.; Hsieh, P.-L.; Zhuang, T.-T.; Liang, Z.-Q.; Zou, C.; Wang, X.; De Luna, P.; Edwards, J. P.; Xu, Y.; Li, F.; Dinh, C.-T.; Zhong, M.; Lou, Y.; Wu, D.; Chen, L.-J.; Sargent, E. H.; Sinton, D. Efficient electrocatalytic conversion of carbon monoxide to propanol using fragmented copper. Nat. Catal. 2019, 2, 251-258.

(38) Roberts, F. S.; Kuhl, K. P.; Nilsson, A. High Selectivity for Ethylene from Carbon Dioxide Reduction over Copper Nanocube Electrocatalysts. Angew. Chem., Int. Ed. 2015, 54, 5179-5182.

(39) Ren, D.; Deng, Y.; Handoko, A. D.; Chen, C. S.; Malkhandi, S.; Yeo, B. S. Selective Electrochemical Reduction of Carbon Dioxide to Ethylene and Ethanol on Copper(I) Oxide Catalysts. ACS Catal. 2015, 5, 2814-2821.

(40) Strehblow, H.-H.; Maurice, V.; Marcus, P. Initial and later stages of anodic oxide formation on $\mathrm{Cu}$, chemical aspects, structure and electronic properties. Electrochim. Acta 2001, 46, 3755-3766. 
(41) Gao, D.; Sinev, I.; Scholten, F.; Arán-Ais, R. M.; Divins, N. J.; Kvashnina, K.; Timoshenko, J.; Roldan Cuenya, B. Selective $\mathrm{CO}_{2}$ Electroreduction to Ethylene and Multicarbon Alcohols via Electrolyte-Driven Nanostructuring. Angew. Chem. Int. Ed. 2019, 58, 17047-17053.

(42) Zhou, Y.; Che, F.; Liu, M.; Zou, C.; Liang, Z.; De Luna, P.; Yuan, H.; Li, J.; Wang, Z.; Xie, H.; Li, H.; Chen, P.; Bladt, E.; Quintero-Bermudez, R.; Sham, T.-K.; Bals, S.; Hofkens, J.; Sinton, D.; Chen, G.; Sargent, E. H. Dopant-induced electron localization drives $\mathrm{CO}_{2}$ reduction to $\mathrm{C}_{2}$ hydrocarbons. Nat. Chem. 2018, 10, 974-980.

(43) Baricuatro, J. H.; Kim, Y.-G.; Tsang, C. F.; Javier, A. C.; Cummins, K. D.; Hemminger, J. C. Selective conversion of $\mathrm{CO}$ into ethanol on $\mathrm{Cu}(511)$ surface reconstructed from $\mathrm{Cu}(\mathrm{pc})$ : Operando studies by electrochemical scanning tunneling microscopy, mass spectrometry, quartz crystal nanobalance, and infrared spectroscopy. J. Electroanal. Chem. 2020, 857, 113704.

(44) Wang, L.; Nitopi, S. A.; Bertheussen, E.; Orazov, M.; Morales-Guio, C. G.; Liu, X.; Higgins, D. C.; Chan, K.; Nørskov, J. K.; Hahn, C.; Jaramillo, T. F. Electrochemical Carbon Monoxide Reduction on Polycrystalline Copper: Effects of Potential, Pressure, and $\mathrm{pH}$ on Selectivity toward Multicarbon and Oxygenated Products. ACS Catal. 2018, $8,7445-7454$.

(45) Clark, E. L.; Resasco, J.; Landers, A.; Lin, J.; Chung, L.-T.; Walton, A.; Hahn, C.; Jaramillo, T. F.; Bell, A. T. Standards and Protocols for Data Acquisition and Reporting for Studies of the Electrochemical Reduction of Carbon Dioxide. ACS Catal. 2018, 8, 6560-6570.

(46) Leonard, M.; Clarke, L. E.; Forner-Cuenca, A.; Brown, S. M.; Brushett, F. Investigating Electrode Flooding in a Flowing Electrolyte, Gas-Fed Carbon Dioxide Electrolyzer. ChemSusChem, 2020, 13, 400-411.

(47) Santamaria, A. D.; Das, P. K.; MacDonald, J. C.; Weber, A. Z. Liquid-Water Interactions with Gas-Diffusion Layer. J. Electrochem. Soc. 2014, 161, F1184-F1193.

(48) Eren, B.; Zherebetskyy, D.; Patera, L. L.; Wu, C. H.; Bluhm, H.; Africh, C.; Wang, L.W.; Somorjai, G. A.; Salmeron, M. Activation of $\mathrm{Cu}(111)$ surface by decomposition into nanoclusters driven by CO adsorption. Science 2016, 351, 475-478.

(49) Kim, Y.-G.; Baricuatro, J. H.; Javier, A.; Gregoire, J. M.; Soriaga, M. P. The Evolution of the Polycrystalline Copper Surface, First to $\mathrm{Cu}(111)$ and Then to $\mathrm{Cu}(100)$, at a Fixed 
$\mathrm{CO}_{2} \mathrm{RR}$ Potential: A Study by Operando EC-STM. Langmuir 2014, 30, 15053-15056.

(50) Huang, J.; Hörmann, N.; Oveisi, E.; Loiudice, A.; De Gregorio, G. L.; Andreussi, O.; Marzari, N.; Buonsanti, R. Potential-induced nanoclustering of metallic catalysts during electrochemical $\mathrm{CO}_{2}$ reduction Nat. Commun. 2018, 9, 3117.

(51) Kim, Y.-G.; Javier, A.; Baricuatro, J. H.; Soriaga, M. P. Regulating the Product Distribution of CO Reduction by the Atomic-Level Structural Modification of the $\mathrm{Cu}$ Electrode Surface. Electrocatalysis 2016, 7, 391-399.

(52) Endrődi, B.; Kecsenovity, E.; Samu, A.; Darvas, F.; Jones, R. V.; Török, V.; Danyi, A.; Janáky, C. Multilayer Electrolyzer Stack Converts Carbon Dioxide to Gas Products at High Pressure with High Efficiency. ACS Energy Lett. 2019, 4, 1770-1777.

(53) Gurudayal; Beeman, J. W.; Bullock, J.; Wang, H.; Eichhorn, J.; Towle, C.; Javey, A.; Toma, F. M.; Mathews, N.; Ager, J. W. Si photocathode with Ag-supported dendritic $\mathrm{Cu}$ catalyst for $\mathrm{CO}_{2}$ reduction Energy Environ. Sci. 2019, 12, 1068-1077.

(54) Ravel, B.; Newville, M. ATHENA, ARTEMIS, HEPHAESTUS: data analysis for Xray absorption spectroscopy using IFEFFIT. J. Synchrotron Radiat. 2005, 12, 537-541.

(55) McCrory, C. C. L.; Jung, S.; Peters, J. C.; Jaramillo, T. F. Benchmarking Heterogeneous Electrocatalysts for the Oxygen Evolution Reaction. J. Am. Chem. Soc. 2013, 135, 16977-16987. 

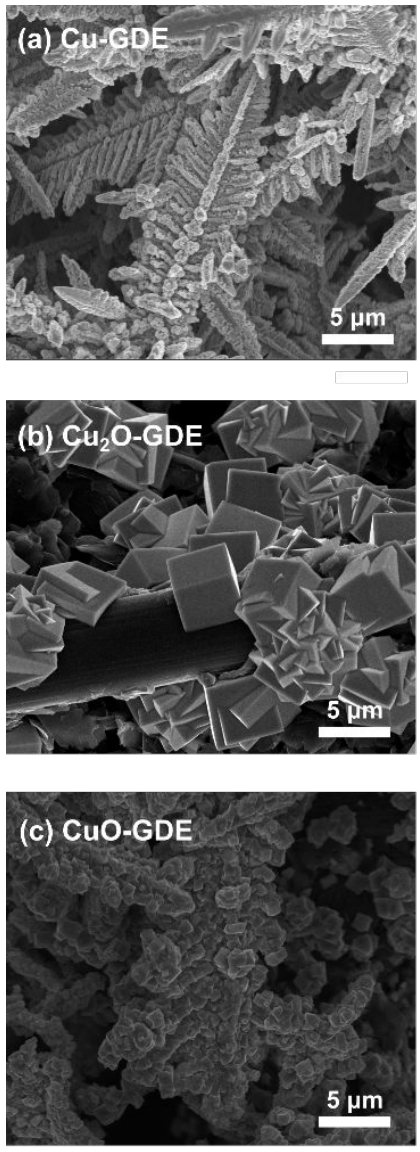
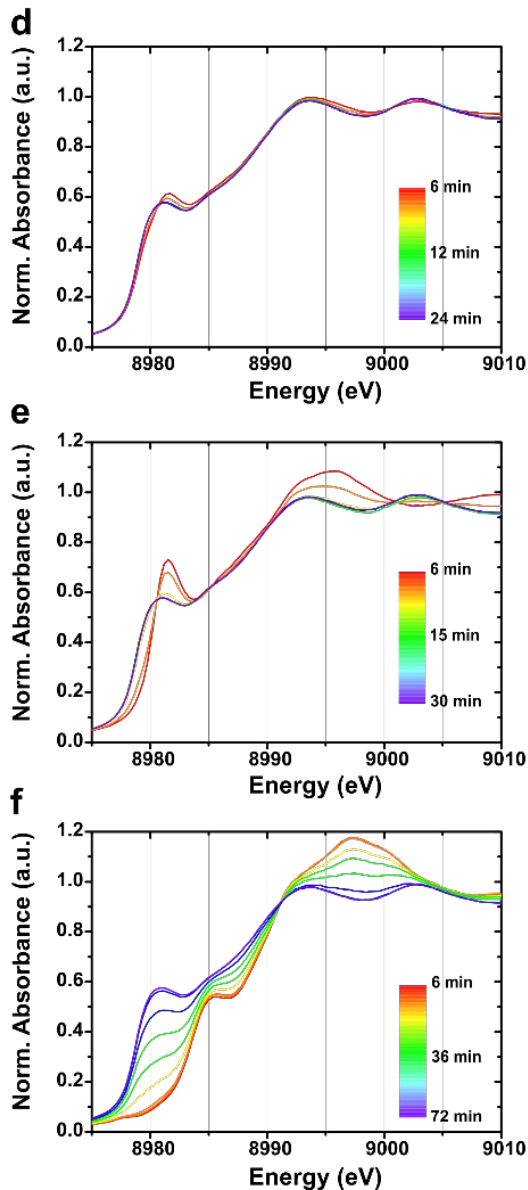
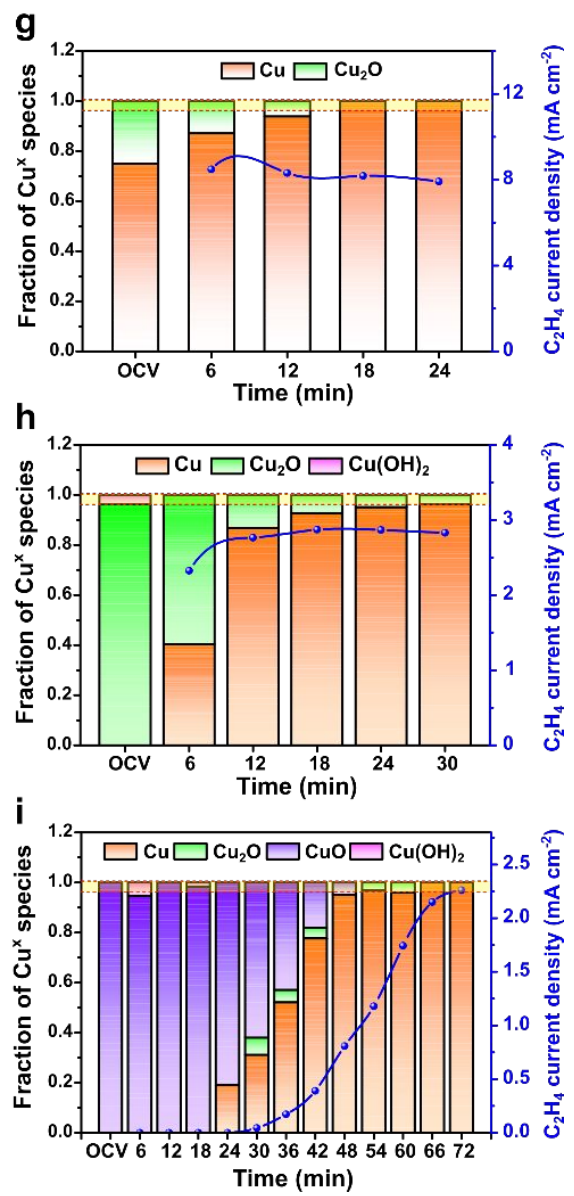

Figure 1. Catalyst structural characterization and operando XANES spectra during CORR. (ac) SEM images of the as-synthesized Cu-GDE (a), $\mathrm{Cu}_{2} \mathrm{O}-\mathrm{GDE}$ (b), and CuO-GDE (c). (d-f) Temporal changes of $\mathrm{Cu}$ K-edge XANES spectra of Cu-GDE (d), $\mathrm{Cu}_{2} \mathrm{O}-\mathrm{GDE}(\mathrm{e})$, and CuOGDE (f) acquired during the CORR at $-2.2 \mathrm{~V}$ vs. $\mathrm{Ag} / \mathrm{AgCl}$. (g-i) The calculated fraction of $\mathrm{Cu}$ oxidation states of $\mathrm{Cu}-\mathrm{GDE}(\mathrm{g}), \mathrm{Cu}_{2} \mathrm{O}-\mathrm{GDE}(\mathrm{h})$, and $\mathrm{CuO}-\mathrm{GDE}$ (i) from LCF analysis with respect to reaction time. $\mathrm{GC}$ measurements for $\mathrm{C}_{2} \mathrm{H}_{4}$ partial current density (blue traces) were synchronized with XANES measurements and collected every 6 minutes. The yellow shaded region represents the estimated error range of up to $4 \%$ in the LCF analysis. The data in $g, h$, and $\mathrm{i}$ are derived from XANES spectra in panels $\mathrm{d}$, e, and $\mathrm{f}$, respectively. 
a
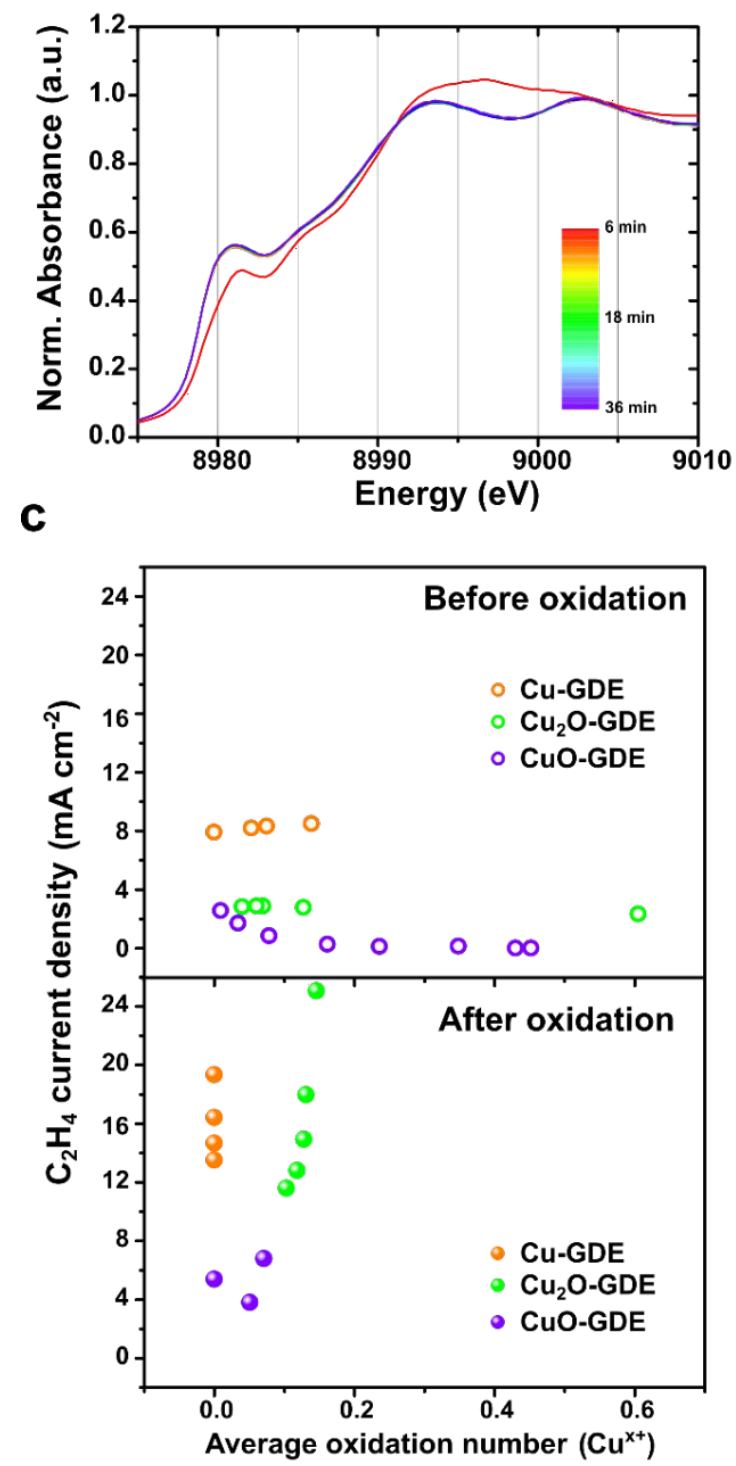

b

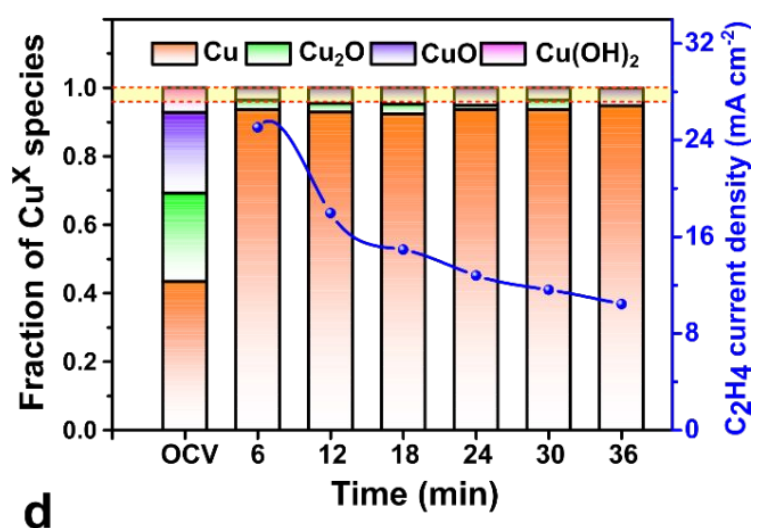

d

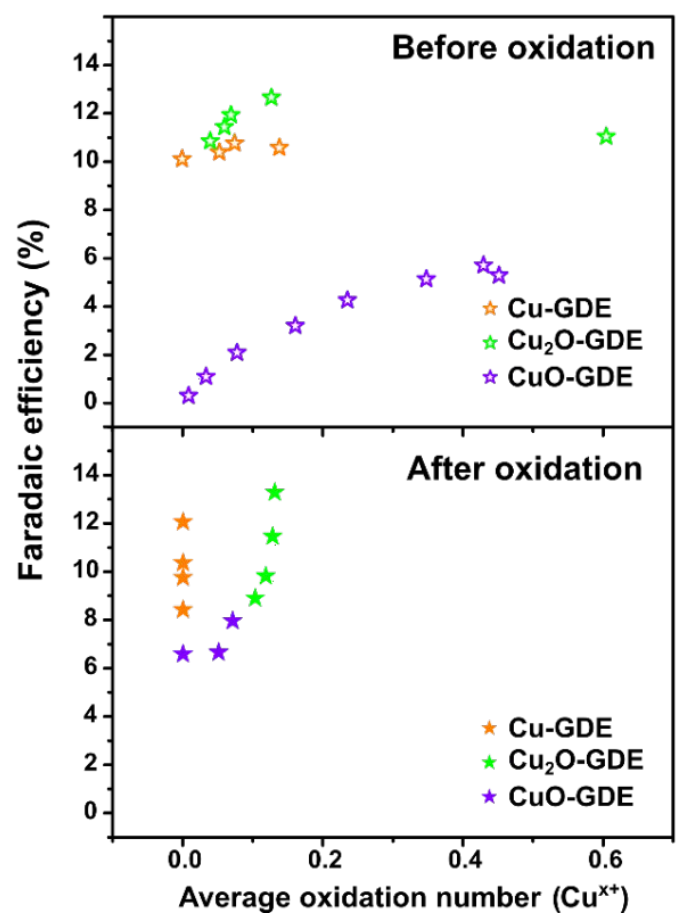

Figure 2. Operando XANES spectra during CORR after electrochemical oxidation. (a) Temporal changes of $\mathrm{Cu}$ K-edge XANES spectra of $\mathrm{Cu}_{2} \mathrm{O}-\mathrm{GDE}$ after applying anodic potential at $1.5 \mathrm{~V}$ vs. $\mathrm{Ag} / \mathrm{AgCl}$ for $5 \mathrm{~min}$. After $6 \mathrm{~min}$, every spectrum overlaps with each other. (b) The calculated fraction of $\mathrm{Cu}$ oxidation states of $\mathrm{Cu}_{2} \mathrm{O}-\mathrm{GDE}$ after electrochemical oxidation. The yellow shaded region represents the estimated error range of up to $4 \%$ in the LCF analysis. (c) $\mathrm{C}_{2} \mathrm{H}_{4}$ partial current density and (d) Faradaic efficiency of $\mathrm{Cu}$ catalysts as a function of $\mathrm{Cu}$ oxidation states before and after electrochemical oxidation. In terms of CORR activity $\left(\mathrm{C}_{2} \mathrm{H}_{4}\right.$ partial current density) and selectivity (Faradaic efficiency), there is no correlation to the $\mathrm{Cu}$ oxidation states. 
a

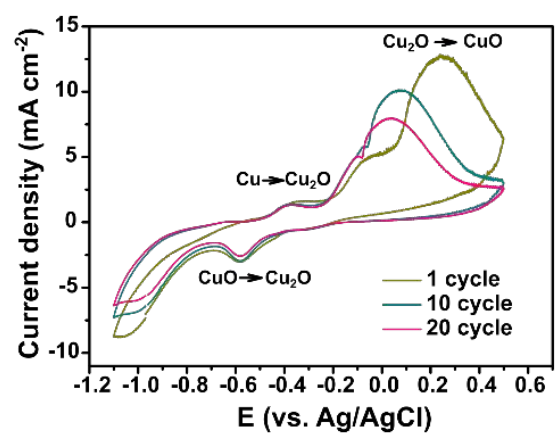

b

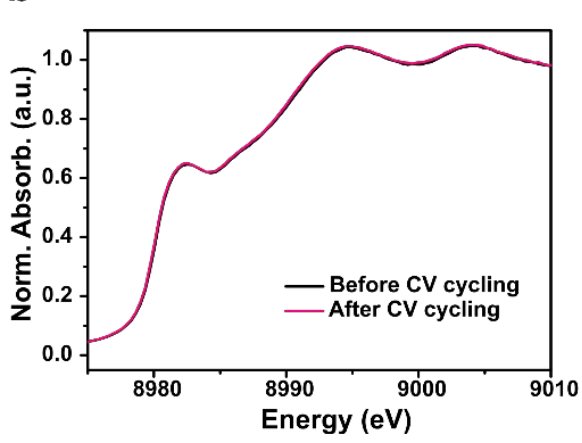

C

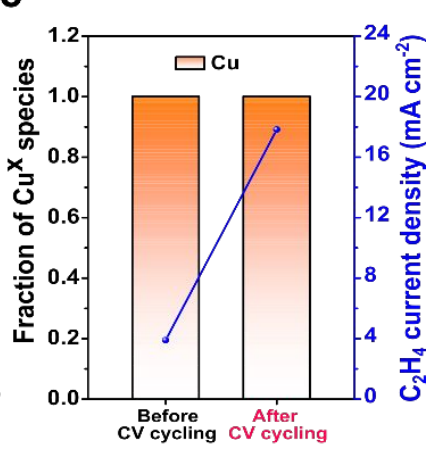

Figure 3. Electrochemical oxidation by using CV cycling. (a) CV curves of Cu-GDE recorded after electrolysis at $-2.2 \mathrm{~V}$ vs. $\mathrm{Ag} / \mathrm{AgCl}$. The anodic peaks related to $\mathrm{Cu}$ oxidation into $\mathrm{Cu}(\mathrm{I})$ and $\mathrm{Cu}$ (II) and reduction are indicated. (b) Operando $\mathrm{Cu}$ K-edge XANES spectra of Cu-GDE before and after $\mathrm{CV}$ cycling. (c) The calculated fraction of $\mathrm{Cu}$ oxidation states before and after $\mathrm{CV}$ cycling and the corresponding $\mathrm{C}_{2} \mathrm{H}_{4}$ partial current density. 
a

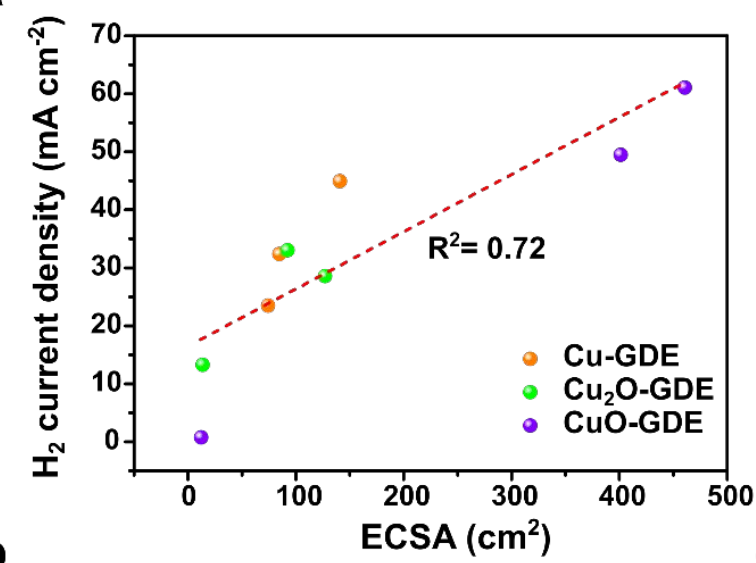

b

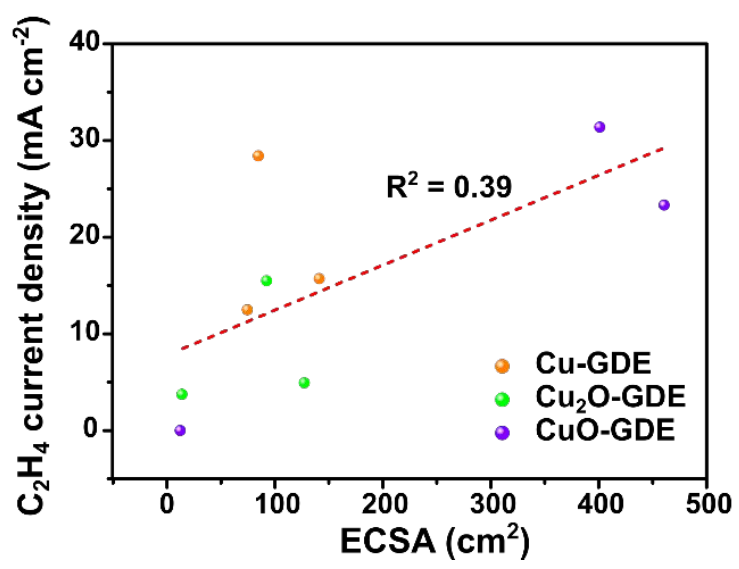

C
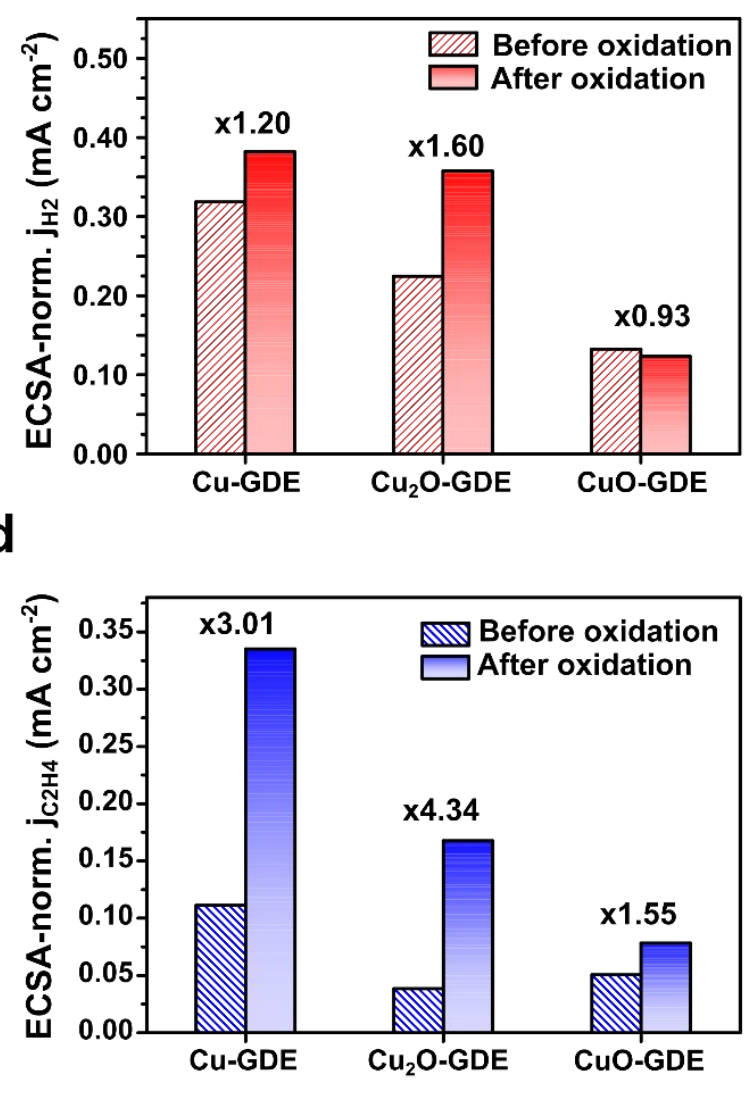

Figure 4. The relationship between ECSA and activities for HER and CORR. (a) $\mathrm{H}_{2}$ and (b) $\mathrm{C}_{2} \mathrm{H}_{4}$ partial current density of $\mathrm{Cu}$ catalysts as a function of ECSA that is estimated by EDLC. Normalized current densities by ECSAs for each $\mathrm{Cu}$ catalyst for $\mathrm{H}_{2}$ (c) and $\mathrm{C}_{2} \mathrm{H}_{4}(\mathrm{~d})$ before and after electrochemical oxidation. 


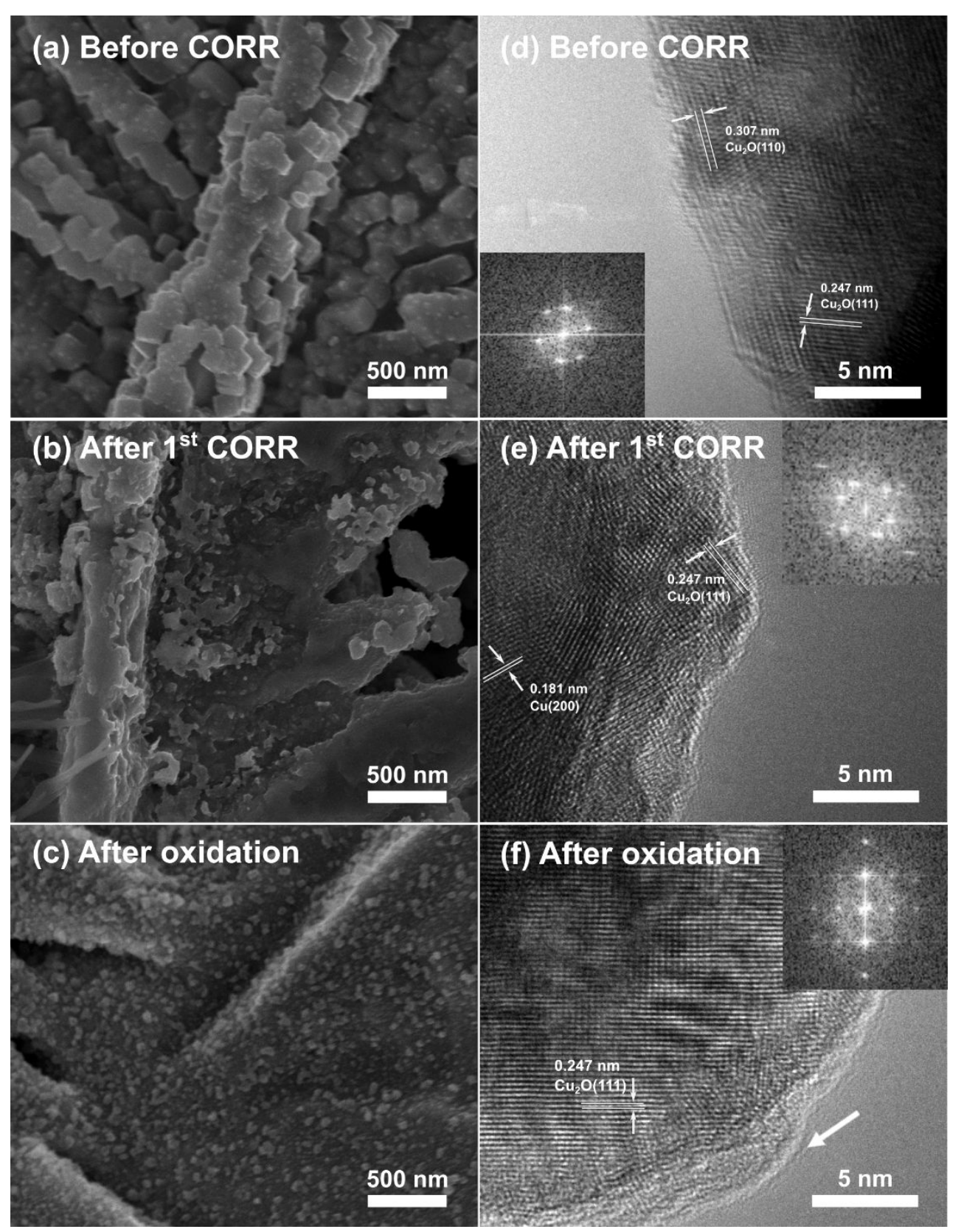

Figure 5. Morphological transformation of Cu-GDE during CORR. (a-c) SEM and (d-f) TEM images of $\mathrm{Cu}-\mathrm{GDE}$ before and after electrolysis and subsequent electrochemical oxidation: $(\mathrm{a}, \mathrm{d})$ as-synthesized $\mathrm{Cu}-\mathrm{GDE}$ before CORR, (b,e) after first CORR under -2.2 V vs. Ag/AgCl taken at $60 \mathrm{~min}$, (c,f) after applying the anodic potential of $1.5 \mathrm{~V}$ vs. $\mathrm{Ag} / \mathrm{AgCl}$ for $5 \mathrm{~min}$. The white arrow indicates an amorphous surface layer on the newly formed nanoparticles after anodic oxidation. The insets of TEM images indicate representative FFT analysis on a selected area to calculate the local d-spacing value. 


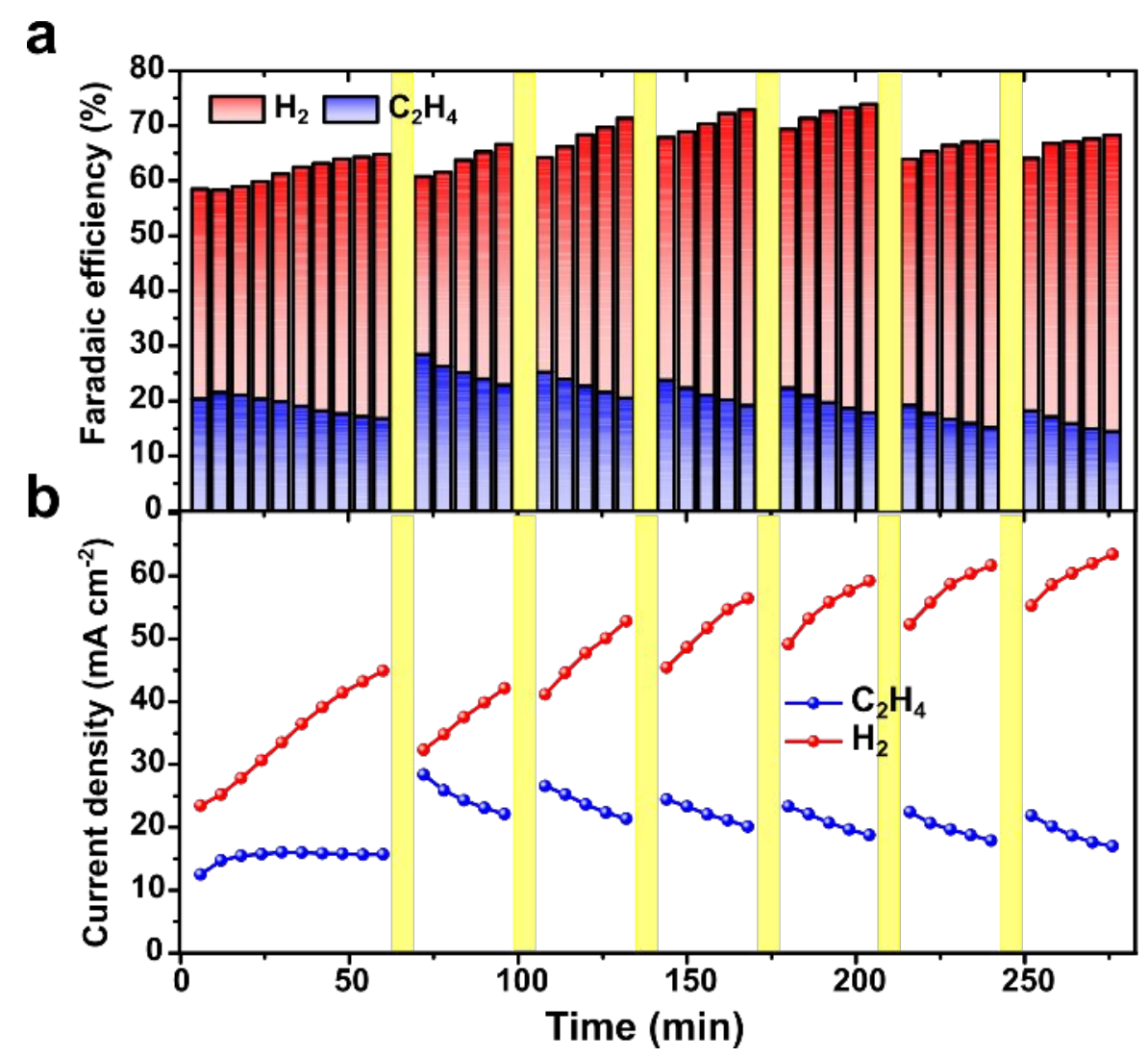

Figure 6. Restoring cell performance by applying anodic oxidation. (a) Faradaic efficiency and (b) partial current density for $\mathrm{H}_{2}$ (red) and $\mathrm{C}_{2} \mathrm{H}_{4}$ (blue) of $\mathrm{Cu}-\mathrm{GDE}$ as a function of repeated catalyst regeneration. During the catalyst regeneration periods (yellow region), the cell was treated by applying the anodic potential of $0.1 \mathrm{~V}$ for 5 min without cell disassembly. 
- Table of Contents (ToC) graphic
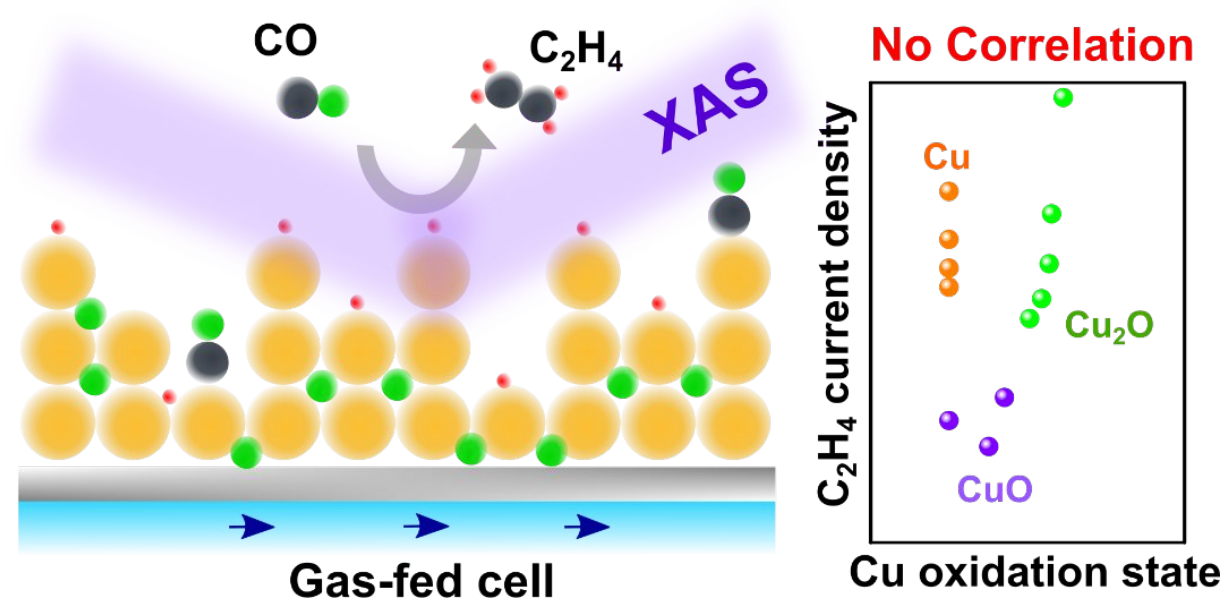